Int. J. Electrochem. Sci., 16 (2021) Article ID: 210816

International Journal of

ELECTROCHEMICAL

SCIENCE

www.electrochemsci.org

\title{
Chemical, Electrochemical and Corrosive Wear Behavior of Nickel-plated Steel and Brass-plated Steel Based Coins from Egypt in Artificial Sweat
}

\author{
Ahmed M. Elzohry ${ }^{1,2}$, Lobna A. Khorshed ${ }^{3}$, Adel Attia ${ }^{3}$, Mahmoud A. Adly', \\ Lamiaa Z. Mohamed ${ }^{4, *}$ \\ ${ }^{1}$ Mechanical Design and Production Engineering Department, Faculty of Engineering, Cairo \\ University, Giza, 12613, Egypt \\ ${ }^{2}$ Egyptian Mint Authority, Dar ElSak St., Eldarasa, Abbasia Cairo, Egypt \\ ${ }^{3}$ Electrochemistry and Corrosion Laboratory, Physical Chemistry Department, National Research \\ Centre, El Buhouth St., Dokki, Cairo, 12622 Egypt \\ ${ }^{4}$ Mining, Petroleum and Metallurgical Engineering Department, Faculty of Engineering, Cairo \\ University, Giza, 12613, Egypt \\ "E-mail: lamylomy@yahoo.com
}

doi: $10.20964 / 2021.08 .33$

Received: 2 April 2021 / Accepted: 31 May 2021 / Published: 30 June 2021

The corrosion behavior of two types of Egyptian coins were investigated. Coins are available as 25 piaster (25P); (nickel-plated steel) and 50 piaster (50P); (brass-plated steel) Egyptian coins. These coins were studied in Artificial Sweat Solution (ASS) by using weight-loss and electrochemical techniques. The ASS was analyzed during weight-loss by Atomic Absorption Spectroscopy during the immersion of these coins for up to seven days. Electrochemical techniques showed that the corrosion rates of 25P were faster than 50P Egyptian coins, while the polarization resistance of 50P (brass plated layer) in the ASS was higher than that of 25P coin (nickel-plated layer). Wear behavior was studied before and after corrosion measurements using the weight-loss method. The optical microscopy was used for the investigation of the surface morphology of these Egyptian coins after immersion in ASS before and after wear. The weight-loss results confirmed that the corrosion rates of $25 \mathrm{P}$ were faster than that of 50P Egyptian coins after immersion for seven days in ASS. Atomic Absorption Spectroscopy results showed that $\mathrm{Ni}$ ions released to unacceptable safety limit. On the other hand, the $\mathrm{Cu}$ and $\mathrm{Zn}$ ions released in ASS did not present any hazard to the human. The specific wear rate of the plating layer of the two Egyptian coins increased by increasing the immersion time in ASS, and the specific wear rate of the 50P Egyptian coins was about three times greater than that of the 25P Egyptian coins.

Keywords: Corrosion behavior; Electrochemical behavior; Wear; Coins; Artificial sweat solution $\underline{\text { FULL TEXT }}$ 
(C) 2021 The Authors. Published by ESG (www.electrochemsci.org). This article is an open access article distributed under the terms and conditions of the Creative Commons Attribution license (http://creativecommons.org/licenses/by/4.0/). 